\title{
NÃO-REGULARIZAÇÃO FUNDIÁRIA DOS TERRITÓRIOS DAS COMUNIDADES QUILOMBOLAS DA BAHIA, UM CASO DE RACISMO?
}

\section{LAND NON-REGULARIZATION OF THE TERRITORIES OF THE QUILOMBOLAS COMMUNITIES OF BAHIA, A CASE OF RACISM?}

Paula Regina de Oliveira Cordeiro Doutoranda no Programa de Pós-Graduação em Geografia da Universidade Federal da Bahia. Membro do Grupo Costeiros - Estudos Socioespaciais da Universidade Federal da Bahia e da Nova Cartografia Social - Núcleo de Estudos em Agroecologia da Universidade Federal do Recôncavo da Bahia Atualmente é professora substituta da Universidade do Estado da Bahia paulareginacordeiro@gmail.com

\section{RESUMO}

Os territórios quilombolas no Brasil enfrentam uma situação de violação de direitos e de negação de suas territorialidades e ancestralidade. Esse estudo levanta e sistematiza dados, argumenta a partir de reflexões teóricas e oriundas do contato direto com diversas comunidades quilombolas argumenta que a não-regularização, a não-proteção e os conflitos nos territórios quilombolas estão inseridos na relação de poder estabelecida a partir da constituição do racismo contemporâneo. Para isso são trazidos alguns casos no Estado da Bahia, como os dos quilombos de Rio dos Macacos, de Dom João, de Graciosa e de São Francisco do Paraguaçu. O racismo é considerado aqui como o elemento explicativo de maior relevo para a não-proteção dos territórios quilombolas.

Palavras-chave: Racismo. Regularização fundiária. Territórios quilombolas.

\begin{abstract}
Quilombola territories in Brazil face a situation of violation of rights and denial of their territoriality and ancestry. This study raises and systematizes data, argues from theoretical reflections and from direct contact with various quilombola communities, argues that non-regularization, non-protection and conflicts in quilombola territories are inserted in the relation of power of formation from the constitution of contemporary racism. For this, some cases are brought to the State of Bahia, such as the quilombos of Rio dos Macacos, Dom João, Graciosa and São Francisco do Paraguaçu. Racism is considered here as the most important explanatory element for the non-protection of quilombola territories.
\end{abstract}

Keywords: Racism. Land regularization. Quilombola territories. 


\section{Introdução}

Os territórios das comunidades tradicionais e quilombolas, em específico, se recolocam no cenário nacional a partir da década de 1970. Com a afirmação dos territórios e da identidade quilombola, novas lutas são constituídas e organizadas no campo brasileiro. $\mathrm{O}$ aparecimento dos povos e das comunidades tradicionais é político e possui como principal impulsionadora a expropriação de territórios, oriunda da expansão das fronteiras do capitalismo no campo.

Alex Ratts (2004) afirma que: “Num país em que ‘custa alto’ ser índio ou negro (...) a autoatribuição de identidade vem acompanhada de demandas pela manutenção ou recuperação de direitos, sobretudo do acesso à terra” (RATTS, 2004, p.79). Nesse sentido, ao reivindicar essas identidades territoriais, os quilombolas são lançados num processo que envolve caminhos tortuosos na direção à regularização e a proteção do território ancestral.

Entre os povos e comunidades tradicionais do Brasil estão quilombolas, pescadores artesanais, marisqueiras e ribeirinhos. Segundo dados do Programa das Nações Unidas para o Desenvolvimento (PNUD), as Comunidades Tradicionais constituem aproximadamente cinco milhões de Brasileiros e ocupam 1/4 do território nacional (SEPPIR, 2013), constituindo-se em significativa população no Brasil.

A classificação dessas populações enquanto "povos e comunidades tradicionais" pode apresentar imprecisão, devido às generalizações, mas será utilizada aqui como reforço a autoatribuição, se caracterizando como identificação política e de reafirmação de direitos (CASTRO, 1997).

Boa parte da população tradicional rural possui o modo de vida integrado com a natureza, possuindo relação direta dos recursos naturais no sentido de garantir aspectos sociais, culturais e de subsistência, com atividades de baixo impacto a essa natureza. Possui baixa inserção no mercado formal ou no circuito superior da economia (SANTOS, 2004), vendo o mercado como não-determinante para o seu modo de vida. Boa parte dos povos e comunidades tradicionais não possuem documentos de propriedade para fortalecer a posse do território (CAÑETE; CAÑETE, 2011). Porém, o principal critério para a identificação destas é a autoatribuição (ou autodefinição). 
É nesse cenário no qual estão inseridos os quilombos que com a sua organização são importantes protagonistas do mundo agrário. Entende-se que com o acionamento da identidade quilombola, o território quilombola deve passar a ser preservado, pois segundo a Constituição Federal de 1988 é garantida através do Art. 68 do Ato das Disposições Constitucionais Transitórias (ADCT) a dominialidade das terras tradicionalmente ocupadas: "Aos remanescentes das comunidades dos quilombos que estejam ocupando suas terras é reconhecida a propriedade definitiva, devendo o Estado emitir-lhes os títulos respectivos". O ADCT passa a ser regulamentado pelo Decreto $\mathrm{n}^{\circ}$ 4.887/2003, o qual define "Os procedimentos administrativos para a identificação, o reconhecimento, a delimitação, a demarcação e a titulação da propriedade definitiva das terras ocupadas por remanescentes das comunidades dos quilombos (...)" (BRASIL, 2003).

Duas contribuições da legislação quilombola são destacadas aqui. A primeira faz referência a prioridade dada ao critério de autoatribuição. Na prática a autoatribuição se dá a partir do reconhecimento coletivo e individual: individual porque o/a sujeito se reconhece enquanto quilombola, coletivo porque a comunidade o/a reconhece enquanto pertencente ao grupo. Outra questão importante é que com o Decreto 4.887/2003, a compreensão de quilombo se desloca da obrigatoriedade das fugas e do caráter punitivo, existentes no tempo da escravidão, tornando os quilombolas sujeitos de direito (CARRIL, 2006).

Vive-se um momento no qual cada vez mais comunidades reivindicam identidades. Segundo os dados da Fundação Cultural Palmares (2017), existem 2.997 comunidades remanescentes de quilombos no Brasil. Destas, 2.523 possuem a certidão quilombola emitida pela Fundação Cultural Palmares (Mapa 1). No Estado da Bahia existem 763 comunidades remanescentes de quilombos; destas, 613 possuem a certidão quilombola. 
Mapa 1: Comunidades quilombolas no Brasil até o ano de 2017

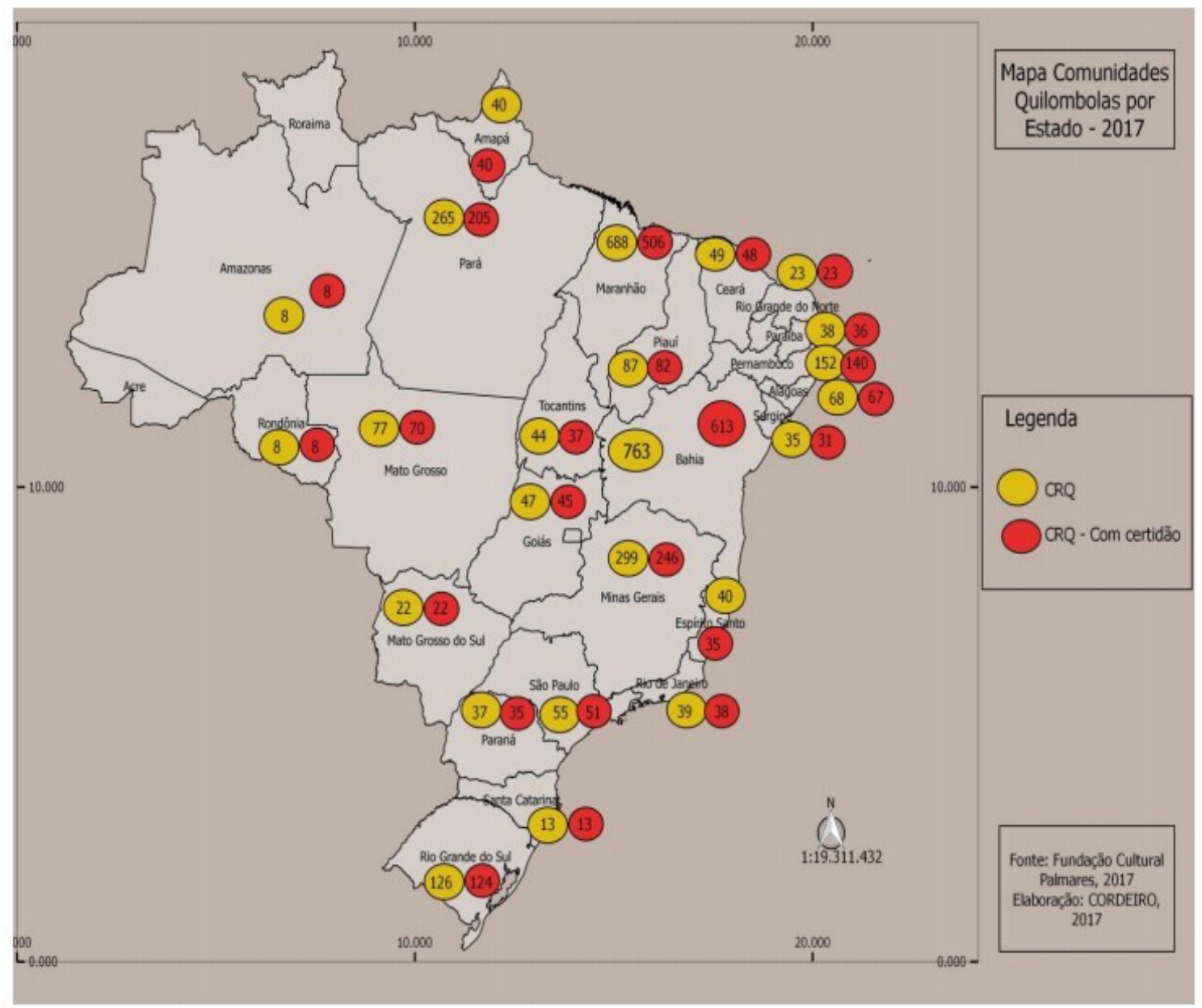

Os fatores para esse crescimento são diversos, mas, sem dúvida, boa parte dos quilombos aciona a identidade em contextos de conflitos territoriais, nos quais a identidade se revela como garantidora de direitos. É, portanto a partir do choque com a tentativa de apropriação privada de seus territórios que boa parte das comunidades (re) constrói sua identidade. Ou como nos diz Frantz Fanon: "Enquanto o negro estiver em casa não precisará, salvo por ocasião de pequenas lutas intestinas, confirmar seu ser diante de um outro." (FANON, 2008, p.103).

Segundo a legislação vigente, essa (re) construção identitária deveria levar a políticas sociais, culturais, territoriais. Porém, durante a análise da situação fundiária das comunidades quilombolas da Bahia percebe-se que o Estado não tem atuado no sentido de garantir os direitos territoriais. Nesse sentido esse artigo pretende investigar 
se a não-regularização dos territórios tradicionais quilombolas, ou melhor, se a nãoproteção ${ }^{1}$ possui relação com o racismo, mais precisamente com o racismo estrutural.

\section{Territórios Quilombolas}

O território quilombola é compreendido pelos sujeitos sociais quilombolas como o espaço necessário à reprodução cultural, religiosa, social, ancestral e econômica, sendo à base da organização social e da identidade cultural de grupos negros. Alex Ratts (2004) alerta que onde há identidade, o confronto está presente:

Por fim, o "jogo de espelhos" da identidade nos remete igualmente a um quadro complexo que se desdobra em situações e escalas variadas. Os encontros ou reencontros entre índios, negros e os outros quase sempre tornam-se confrontos perceptíveis nos planos da linguagem, dos códigos simbólicos e da dimensão espacial. Não raramente emergem como conflitos territoriais e étnicos. Os outros aqui referidos o são sempre dentro de um quadro situacional, relacional ou contextual. (RATTS, 2004, P. 80).

Ao pensar com Alex Ratts pode-se concluir que o território quilombola, no entanto, é também um espaço de disputas e conflitos. Portanto o território quilombola está localizado no confronto entre modos de vida, entre disputas pela produção e reprodução de determinada porção do espaço. É na disputa, no confronto entre os poderes que o território quilombola ganha contornos e novos relevos.

Fato comprobatório é que conjuntamente com a crescente autoatribuição dos povos vivencia-se um quadro da não-titulação dos territórios quilombolas. Segundo o decreto 4.887/2003, há procedimentos para a identificação, o reconhecimento, a delimitação, a demarcação e a titulação da propriedade definitiva das terras ocupadas por remanescentes das comunidades dos quilombos.

O processo de organização das comunidades quilombolas em torno da identidade quilombola é, sem dúvida, o primeiro momento da regularização fundiária dos territórios quilombolas. Posteriormente a associação comunitária solicita a certidão de autorreconhecimento quilombola a Fundação Cultural Palmares. A comunidade apresenta a certidão ao Instituto de Colonização e Reforma Agrária (Incra). A primeira

\footnotetext{
1- Os territórios das comunidades de quilombos devem ser protegidas e receber políticas públicas sendo regularizadas ou não.
} 
etapa para a regularização do território é a elaboração do Relatório Técnico de Identificação de Delimitação (RTID), que consiste em levantamentos e estudos fundiários, cartográficos, antropológicos, ecológicos, geográficos, socioeconômicos, históricos obtidos em campo e junto a instituições de caráter público ou privado. $\mathrm{O}$ objetivo principal do RTID é identificar os limites das terras das comunidades remanescentes de quilombos.

A fase seguinte é a publicação do RTID, no qual os interessados terão 90 dias para contestarem o Relatório junto à Superintendência Regional do Incra. Do julgamento das contestações caberá recurso único ao Conselho Diretor do Incra, no prazo de 30 dias. A próxima fase é a portaria de reconhecimento, no qual há a publicação de portaria do Presidente do Incra no Diário Oficial da União (DOU) e dos estados. Na publicação estará descrita os limites do território quilombola. Após a publicação caso existam imóveis privados (títulos ou posses) no território tradicional, é necessária a publicação de Decreto Presidencial de Desapropriação por Interesse Social. Esses imóveis serão vistoriados e avaliados conforme o preço de mercado e receberão indenização em dinheiro.

A titulação do território é o coroamento desse processo. Aqui o presidente do Incra realizará a titulação mediante a outorga de título coletivo, imprescritível e próindiviso à comunidade, em nome da associação comunitária. Apesar de poder ser sintetizado em poucas linhas, o caminho pela titulação percorrido pelas comunidades quilombolas pode se arrastar no tempo. Os dados mostram o número reduzido de comunidades quilombolas que conseguem chegar à fase final, ou seja, que conquistam a titulação quilombola.

Se de 2005 até 2017 foram emitidas 2.455 certidões quilombolas, segundo os dados do Incra, no mesmo período, foram elaborados 259 RTIDs, com a publicação de 82 decretos, 141 portarias e emissão de 116 títulos, destes 99 são títulos parciais e apenas 17 quilombos tiveram a titulação completa de seus territórios (Quadro 1).

Quadro 1: Dados da Regularização Fundiária no Brasil 2005-2017

\begin{tabular}{|c|c|c|c|c|c|}
\hline \multirow{2}{*}{ Certidões Quilombolas } & \multirow{2}{*}{ RTID Elaborados } & \multirow{2}{*}{ Decretos } & \multirow{2}{*}{ Portarias } & \multicolumn{2}{|c|}{ Títulos } \\
\hline & & & & Parciais & Integral \\
\hline $2.455(100 \%)$ & $259(10 \%)$ & $82(3 \%)$ & $141(6 \%)$ & $99(4 \%)$ & $17(0,7 \%)$ \\
\hline
\end{tabular}


$\mathrm{Na}$ Bahia, no mesmo período foram certificadas 596 comunidades quilombolas, destas, no período entre 2004 e 2018, 319 comunidades abriram processos no Incra para a regularização fundiária, segundo dados do Incra entre 2005 e 2018, 37 comunidades possuem processos em andamento, destas 16 possuem RTIDs elaborados ou em fase de elaboração, 7 possuem a portaria publicada, 8 possuem decretos publicados, 3 possuem a Concessão do Direito Real de Uso (CDRU), apenas 3 possuem a titulação parcial dos seus territórios e nenhum quilombo possui a titulação integral de seu território, o que significa que na Bahia existem 245 processos paralisados no Incra, ou melhor existem 245 territórios (76,80\%) esperando por regularização fundiária na Bahia (Quadro 2).

Quadro 2: Dados da Regularização Fundiária na Bahia 2005 - 2018

\begin{tabular}{|c|c|c|c|c|c|c|c|c|c|}
\hline \multirow{2}{*}{ Certidiòes Quilombolas } & \multirow{2}{*}{ Entrada no Incra } & \multirow{2}{*}{ Processo em andamento } & \multirow{2}{*}{ RTID Elaborado } & \multirow{2}{*}{ Portaria (DOC) } & \multirow{2}{*}{ Dereto (DOC) } & \multirow{2}{*}{ CDRT } & \multicolumn{2}{|c|}{ Titulo } & \multirow{2}{*}{ Processo paralisisalo } \\
\hline & & & & & & & Parcial & Integral & \\
\hline 596 & $319(100 \%)$ & $37(11,0 \% 0)$ & $16(5,01 \%)$ & $7(2,19)$ & $8(2,50 \%)$ & $3(0,9480)$ & $3(0,919)$ & 0 & $245(76,800 \%)$ \\
\hline
\end{tabular}

Obs: Os dados referentes as certidões quilombolas são do período de 2004 a 2017.Fonte: Incra, 2019 Elaboração: CORDEIRO, 2019

É perceptível a disparidade entre o reconhecimento da identidade quilombola e a garantia de seus direitos territoriais. Os dados apresentados acima são alarmantes, pois mostram a negligência com que estão sendo tratados os territórios quilombolas no Brasil. Se no Brasil, até 2017 existiam apenas 116 titulações territoriais esse número piora quando percebe-se que destes apenas 17 possuíam a titulação integral de seus territórios. Na Bahia, território com expressiva concentração quilombola, nenhum quilombo teve seus direitos territoriais respeitados. A não titulação ou a titulação parcial dos territórios quilombolas se tornou norma nos processos de regularização fundiária, contrariando o decreto 4.887/2003, deixando esses territórios vulneráveis e atuando no sentido de conferir legalidade às invasões externas aos territórios quilombolas.

Em pesquisa pode-se perceber que todos os 37 quilombos que estão com processos em andamento no Incra, na Bahia, possuem conflitos territoriais, incluindo aqueles com titulação parcial do território. As situações de conflito variam desde a tentativa de expulsão e violência por fazendeiros, quanto por implantações de megaempreendimentos como a Ferrovia de Integração Oeste-Leste (FIOL), o Porto de Aratu, áreas de extração de gás natural, petróleo e minérios, por conflitos com as forças 
$\operatorname{armadas}^{2}$, além de conflitos causados pela expansão do turismo nos territórios tradicionais.

A não-regularização fundiária destes territórios na Bahia é fruto do entendimento de que esses devem estar disponíveis para o mercado. Essa visão da propriedade privada da terra é fruto da organização do sistema-mundo moderno-colonial (QUIJANO, 2005). Para a constituição do mundo moderno-colonial vivenciado atualmente, foi necessário o estabelecimento de normatizações que visavam assegurar o poder político, econômico, social e cultural do europeu e posteriormente norteamericano sobre o restante do globo. Para isso, como já demonstrou Yves Lacoste (1988), o controle territorial é indispensável. Assim, lançou-se mão da hierarquização e subjugação dos povos cujos territórios deveriam ser redirecionados aos interesses dos colonizadores, nas palavras de Vandana Shiva: "o desaparecimento do saber local por meio de sua interação com o saber ocidental dominante acontece em muitos planos, por meio de muitos processos. Primeiro fazem o saber local desaparecer simplesmente não o vendo, negando sua existência." (SHIVA, 2003, p.23).

A medida que o saber local consegue se restabelecer e re-existir ocorre a tentativa de descaracterizá-lo, subjugando-o novamente:

Quando o saber local aparece de fato no campo da visão globalizadora, fazem com que desapareça negando-lhe o status de um saber sistemático e atribuindo-lhe os adjetivos de "primitivo" e anticientífico. Analogamente o sistema ocidental é considerado o único "científico e universal". Entretanto, os prefixos "científico" para os sistemas modernos e "anticientífico" para os sistemas tradicionais de saber tem pouca relação com saber e muita com poder (SHIVA, 2003, p. 23).

Com a pretensão de tornar-se universal, o atual sistema criou um imaginário de neutro, científico e moderno, segundo Shiva (2003):

(...) o sistema dominante também é um sistema local, com sua base social em determinada cultura, classe e gênero. Não é universal em

\footnotetext{
2- Como no caso do Quilombo Rio dos Macacos, em conflito desde pelo menos a década de 1970 com a Marinha do Brasil. O território tradicional de Rio dos Macacos foi reduzido de 301 hectares para 104 hectares e teve a portaria publicada no Diário Oficial da União (DOU). Um estudo fora realizado em Dissertação de mestrado em 2018, com o título: “Essa terra é para filh@s e net@s, não vende e não pode trocar: A disputa entre o território tradicional quilombola-pesqueiro de Rio dos Macacos e o território militarizado da Marinha do Brasil".
} 
sentido epistemológico. É apenas a versão globalizada de uma tradição local extremamente provinciana. Nascidos de uma cultura dominadora e colonizadora, os sistemas modernos de saber são, eles próprios, colonizadores. (SHIVA, 2003, p. 22).

A ideia de moderno e de progresso afirma que todas as sociedades têm um destino em comum: o desenvolvimento. E, para que o desenvolvimento seja alcançado é necessário que os territórios estejam disponíveis para o seu principal agente: o mercado. A não-regularização, ou melhor, a não proteção dos territórios quilombolas torna-se norma.

\title{
Territórios Quilombolas e Racismo
}

O conflito em torno dos territórios quilombolas é parte do processo de expansão das fronteiras do capital. Essas fronteiras do capital necessitam romper, fragmentar, avançar sobre as fronteiras étnicas, sejam elas dos povos indígenas, quilombolas, pescadores, fundos e fechos de pasto ou de outras comunidades tradicionais.

No caso estudado trata-se de que a população negra é aquela a habitar os territórios quilombolas. A raça não é apenas um dado, mas um fator importante para a compreensão do processo em curso. Renato Emerson dos Santos afirma que:

\begin{abstract}
A raça é um critério básico de classificação da população mundial, fundamental para afirmação do sistema capitalista (QUIJANO, 2007). Sustentada (durante um tempo) ou superada (mais recentemente) pelo saber do campo da Biologia, é sua pertinência social em projetos de poder que sustenta sua permanência, a despeito de ter ou não ter lastro em saberes científicos. É neste sentido que mesmo com a negação da pertinência de diferenças biológicas entre seres humanos que permitam sua classificação em grupos raciais, no cotidiano das relações sociais a raça continua a ser um princípio regulador de comportamentos e relações: reconhecer a igualdade biológica não necessariamente impulsiona reconhecimento de igualdade social (SANTOS, 2017, p. 59).
\end{abstract}

A expulsão, a apropriação privada e a negação de direitos aos povos negros e indígenas estão na gênese da formação socioespacial brasileira e apesar das conquistas inscritas na Constituição Federal de 1988, a hierarquização das populações através da raça e etnia continua a transformar os territórios dessas populações em algo que merece ser conquistado, quando não colonizado. Carlos Moore, afirma que “(...) o fenótipo, 
desde os mais longínquos períodos, determina um papel orientador das ações de violência iniciadas por disputas de recursos e território entre populações visivelmente diferentes" (MOORE, 2012, p.130).

A operacionalização do racismo serve, portanto, para assegurar a propriedade e preservação monopolista das riquezas vitais da sociedade (MOORE, 2012). No caso do Brasil, o qual está inserido na divisão internacional do trabalho como um país exportador de commodities, os territórios com maiores riquezas naturais, possuem então as riquezas vitais da nossa sociedade. Em texto recente, Paulo Alentejano afirma que:

A tropicalidade (abundância de sol e água) dominante em nosso território garante a intensidade dos processos de fotossíntese, acelerando o metabolismo das plantas e seu processo de crescimento, o que favorece ainda mais à acumulação de capital na agricultura, por contribuir para reduzir a diferença entre tempo de trabalho e tempo de produção (ALENTEJANO, 2015, p. 06).

As palavras de Alentejano reafirmam a compreensão de que os conflitos fundiários, com destaque para os conflitos nos territórios quilombolas são uma necessidade de expansão do capital. O racismo, assim como o capital evolui constantemente (CESAIRE, 1971), se outrora fora a escravização, ou a Lei de Terras de $1850^{3}$, a atual necessidade da exploração intensa e mecanizada da natureza coloca mais uma vez a necessidade dos sujeitos hegemônicos em negar e exterminar o diferente. Dessa forma ora afirmam as comunidades quilombolas como atrasadas, como impedimento ao desenvolvimento, necessitando serem estas superadas, ora tentam descaracterizá-las. Isso é percebido nas palavras de Jair Bolsonaro, atual presidente da República que em 2017 demonstra suas impressões sobre uma comunidade quilombola em Eldorado (São Paulo): “O afrodescendente mais leve lá pesava sete arrobas. Não fazem nada. Eu acho que nem para procriar eles servem mais” (BRASIL DE FATO, $2019)^{4}$.

\footnotetext{
3. A Lei de Terras de 1850 é conhecida por ter antecedido e preparado a propriedade privada para não absorver os africanos escravizados que seriam libertos em 1888, com a abolição formal da escravatura.

4_ Ver matéria completa em: https://www.brasildefato.com.br/2019/06/07/quilombolas-que-foram-alvode-bolsonaro-criticam-arquivamento-de-processo-de-racismo/.
} 
Da mesma forma que as instituições nacionais da então recém República brasileira “(...) defendiam que o desenvolvimento e o crescimento da República fundada em 1889 - estariam vinculados ao branqueamento da sua população." (CORRÊA, 2017, p.117). Os capitalistas brasileiros e estrangeiros defendem que o desenvolvimento e o progresso da atual república só existirão quando a propriedade da terra seja assegurada a quem der lucro. Novamente reproduz-se as palavras de Jair Bolsonaro:

Seu povo, seus irmãos, têm problemas. E o grande problema chama-se governo federal. Eles querem ser libertos, para ter liberdade para poder trabalhar dentro da sua comunidade, acho até que se quiser vender aquela área quilombola, que venda, opinião minha. Se quiser explorar, tirar por exemplo minério, ter maquinário, a exemplo do seu irmão fazendeiro do lado, se quiser, poder explorar de forma racional seus recursos naturais igual ao fazendeiro do lado. (OGLOBO, 2018)5.

Não é de se espantar que um país que até a Constituição de 1945 possuía decretos e artigos que afirmavam a importância da imigração para o branqueamento da nação ${ }^{6}$ produza argumentos para a Ação Direta de Inconstitucionalidade (ADI) 3239 - a ADI quilombola - e para a não-regularização (e não-proteção) dos territórios quilombolas.

A ADI 3239 discute a constitucionalidade do já citado Decreto Federal $n^{\circ}$ 4887/037 , ajuizada em 2004 pelo Partido da Frente Liberal (PFL), atual Democratas, contém 11 volumes e 1600 páginas. A ADI quilombola questiona dois princípios fundamentais do Decreto, o primeiro é o critério de autoatribuição para a identificação de quilombos e o segundo é a existência de "critérios de territorialidade indicados pelos remanescentes das comunidades de quilombos" para medição e demarcação destas terras (art. $2^{\circ}, \S 3^{\circ}$ ). Após 14 anos, o Supremo Tribunal Federal (STF) declarou a validade do Decreto 4.887/2003, a Ação Direta de Inconstitucionalidade 3239 foi julgada improcedente por oito ministros. O ministro e relator do caso Cezar Peluso

5. Ver matéria completa em: https:/oglobo.globo.com/brasil/bolsonaro-defende-que-areas-quilombolaspossam-ser-vendidas-22859321.

6_ “Atender-se-á, na admissão dos imigrantes, à necessidade de preservar e desenvolver, na composição étnica da população, as características mais convenientes da sua ascendência europeia, assim como a defesa do trabalhador nacional." (DECRETO N.7.967, 1945)

7- Decreto que regulamenta o procedimento de titulação dos territórios quilombolas no Brasil. 
(aposentado), foi o único voto pela total procedência da ação. Cezar Peluso afirma que não se poderia ignorar o crescimento de conflitos agrários e que o Decreto 4.887/2003, por representar a usurpação de direitos de propriedade privada, pode levar o incitamento à revolta.

A decisão do relator demonstra que não há compreensão dos quilombolas enquanto sujeitos de direitos, mas sim como usurpadores de direitos de propriedade privada. A questão que se coloca é entender que a propriedade da terra no Brasil sempre foi reconhecida para aqueles que detinham o poder político e econômico ao longo do tempo. Sem dúvida, essas pessoas não são negras, nem indígenas. O racismo opera aqui com seu caráter institucional. Nesse sentido, segundo Sílvio Almeida: “o poder é elemento constitutivo das relações raciais, mas não somente o poder de um indivíduo de uma raça sobre outro, mas de um grupo sobre outro, algo possível quando há o controle direto ou indireto de determinados grupos sobre o aparato institucional" (ALMEIDA, 2018, p. 36).

Ao tentar romper essa ordem da organização da propriedade privada, os quilombos no Brasil ameaçam romper também a ordem racial do poder. É necessário remeter as palavras de Vandana Shiva, algumas linhas acima, contextualizando com a situação vivenciada pelos quilombos na contemporaneidade. A história dos quilombos no Brasil pode ser dividida em três momentos: (I) perseguição, punição e criminalização até 1888, com a abolição da escravatura (MOURA, 1981); (2) apagamento no pósabolição até aproximadamente a década de 1970 (ANJOS, 2004); (3) emergência e consolidação de direitos com a Constituição Federal de 1988. Se desde a introdução dos primeiros africanos escravizados no Brasil reinou a tentativa de apagamento cultural, através da aculturação ou do genocídio, a partir da abolição da escravatura a tentativa foi de apagar os sujeitos que foram subalternizados "simplesmente não o [os] vendo, negando sua [suas] existência [existências]" (SHIVA, 2003, p.23) e quando essas existências "aparece [aparecem] de fato no campo da visão globalizadora, fazem com que desapareça [desapareçam]”' (SHIVA, 2003, p.23).

O questionamento em relação a autoatribuição na ADI 3239 é uma manifestação à nível nacional do que acontece nos territórios. O questionamento da identidade quilombola é constante nos processos de regularização fundiária, principalmente quando esses territórios estão em conflitos. Se a ADI 3239 foi derrubada, o questionamento 
ocorre nos territórios mesmo quando os quilombos apresentam a certidão emitida pela Fundação Cultural Palmares.

$\mathrm{Na}$ Bahia, por exemplo, inúmeros quilombos de deparam com esse questionamento. O Quilombo Rio dos Macacos, localizada no município de Simões Filho, em conflito com a Marinha do Brasil teve sua identidade questionada pelo juiz Evandro Reimão que ao julgar uma ação da Marinha afirma serem os quilombolas ocupantes ilegais que se escondem por trás da identidade quilombola. Além do juiz, a Revista Veja em maio de 2014 publicou a notícia com o título "O falso quilombo do ministro", reafirmando a tese de que a identidade quilombola na comunidade de Rio dos Macacos seria falsa (Figura 1).

Figura 1: Reportagem da Revista Veja em 2014

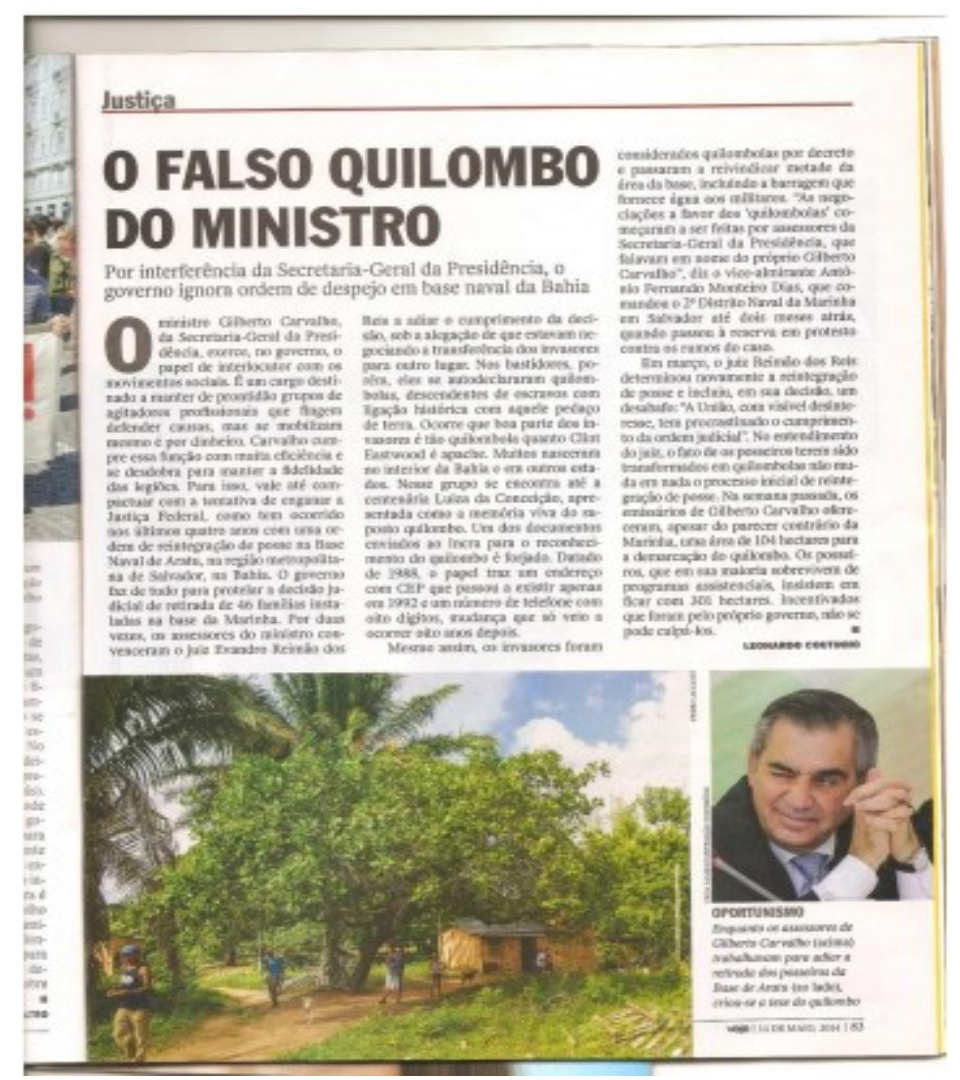

O território quilombola de São Francisco do Paraguaçu, situado no município de Cachoeira, em conflito com fazendeiros oriundos das oligarquias nacionais também teve sua identidade questionada. Foram diversas tentativas de ações de reintegração de posse ordenadas pelas justiças estadual e federal e ações violentas levadas a cabo por jagunços 
e policiais da Polícia Militar (PM) do Estado da Bahia. Todas as ações tinham como princípio o questionamento seguido de negação da identidade quilombola. Além dos impedimentos ocasionados pela articulação dos fazendeiros com a justiça, entrou em cena a TV Globo, que em reportagem veiculada em $2007^{8}$ afirmou que houve fraude na emissão da certidão da Fundação Cultural Palmares, pois segundo a emissora, a identidade quilombola em questão é falsa.

Figura 2: Reportagem da TV Globo em 2007

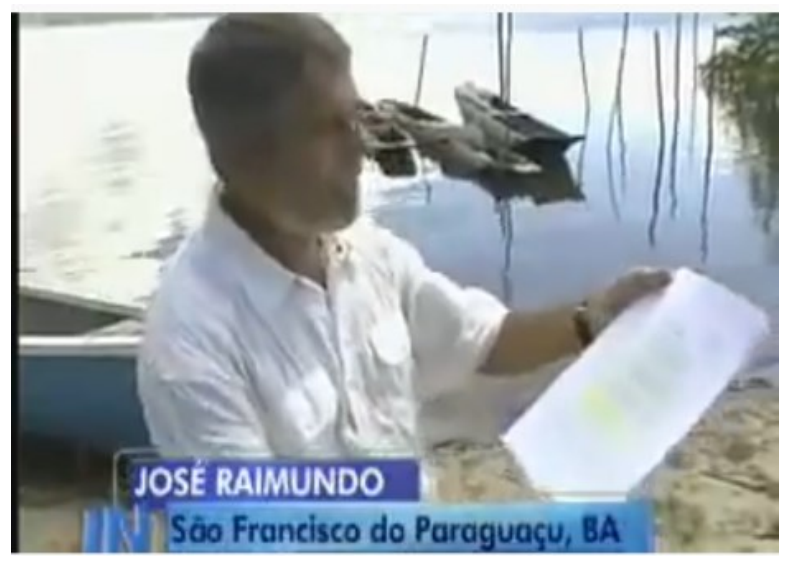

No Baixo Sul da Bahia, no município de Taperoá o quilombo de Graciosa em conflito com a expansão do turismo e da privatização das áreas de pesca e de agricultura também teve o processo de regularização fundiária interrompido pela decisão judicial do juiz Evandro Reimão questionando e negando também a condição desses enquanto quilombolas.

Esse mesmo juiz também afirmou a condição de falsa a identidade quilombola da comunidade de Dom João, no município de São Francisco do Conde. Nessa comunidade, o conflito se instaura tanto pela presença de fazendeiros, pelos derramamentos de resíduos da Petrobras, quanto pela construção de autódromo pelo Governo do Estado da Bahia.

Poder-se-ia passar muitas linhas pelo tortuoso caminho percorrido pelos quilombos na Bahia, mas se da emissão da certidão da Fundação Cultural Palmares até a elaboração do RTID o rio corre e muitas vezes não chega a foz, o mesmo acontece quando há a publicação dos Relatórios dessas comunidades.

\footnotetext{
8. Link para reportagem: https://www.youtube.com/watch?v=Y6C1YtZQBq0
} 
Por exemplo, em 2012, o Incra apresentou o RTID do quilombo Rio dos Macacos e identificou 301 hectares como território quilombola. No entanto, segundo os quilombolas sua territorialidade chega até aos 900 hectares. Sendo publicado em 2014, após exigência do Ministério Público Federal, o território a ser destinado para a titulação abarca 104 hectares desfragmentados ${ }^{9}$. O mapa abaixo (Mapa 3), apresenta a desfragmentação do território. A linha preta representa os 301 hectares inicialmente reconhecidos pelo Incra já as poligonais brancas representam os 104 hectares. O território será dividido em duas glebas sem continuidade e articulação territorial: a primeira, localizada na área norte-noroeste do território, possui 98,2755 ha; a segunda possui 5,8057 ha e está localizada a sudoeste. A princípio essa proposta ignora e desrespeita a decisão quilombola contrária a fragmentação territorial. Não se trata apenas da questão quantitativa do território, mas também das questões culturais e identitárias: a existência de um território continuo no Quilombo - "Um Quilombo só”, é condição necessária para a sua reprodução. A fragmentação desencadeará um processo de fratura ou quebra, o território que era um se transformará em dois fragmentos, são duas partes quebradas, isoladas, desunidas, desconectada. Atualmente a comunidade possui portaria publicada no Diário Oficial da União (DOU).

\footnotetext{
9- Um estudo fora realizado em Dissertação de mestrado em 2018, com o título: "Essa terra é para filh@s e net@s, não vende e não pode trocar: A disputa entre o território tradicional quilombola-pesqueiro de Rio dos Macacos e o território militarizado da Marinha do Brasil”.
} 
Mapa 3: Fragmentação do território quilombola de Rio dos Macacos

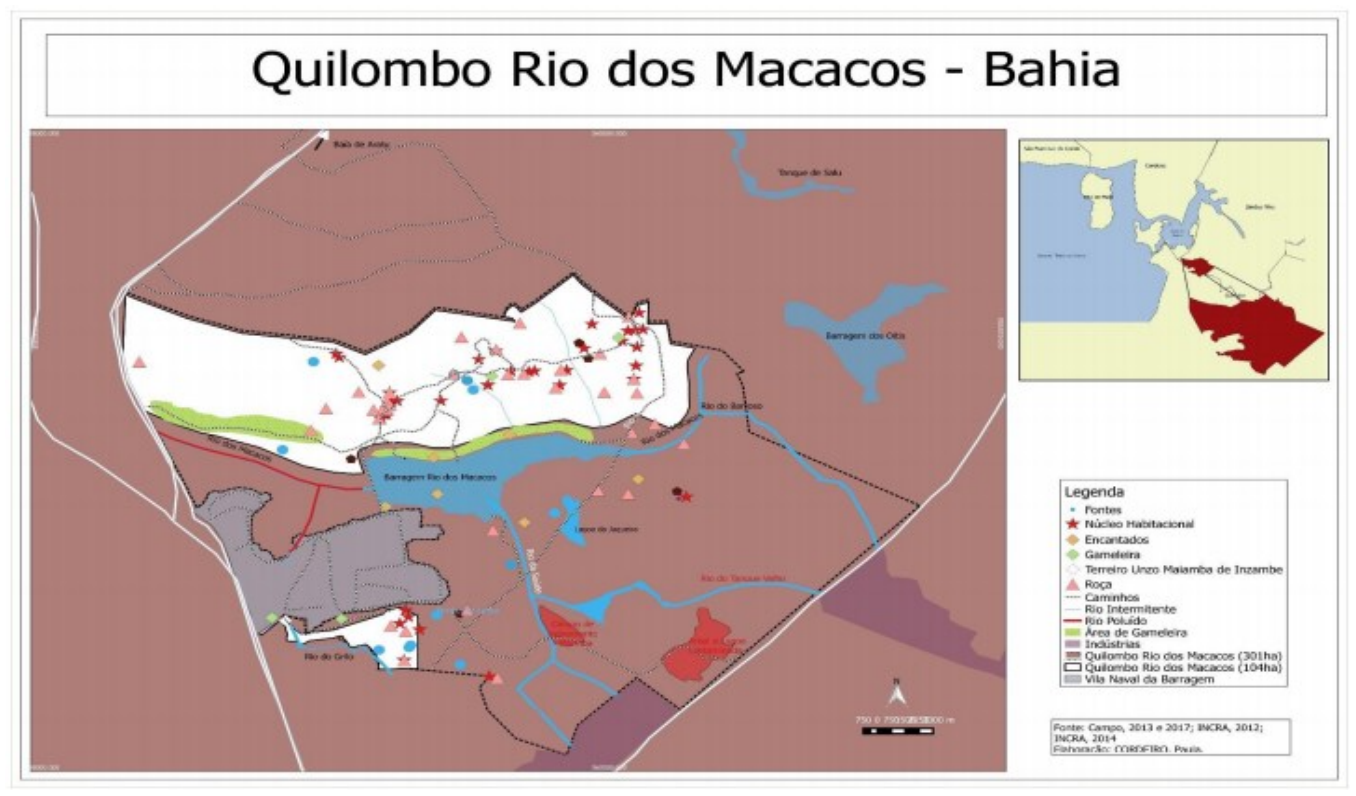

Existem também na Bahia três quilombos que possuem a titulação parcial dos seus territórios, como fora visto anteriormente, nenhum quilombo apresenta a titulação territorial integral. Essa situação revela não apenas o não cumprimento da Constituição Federal de 1988, mas de que há algo mais poderoso que a carta magma, aqui esse "algo" é o racismo. Este entendido não apenas como institucional, mas como racismo estrutural. Segundo Silvio Almeida:

(...) se é possível falar de um racismo institucional, significa que, de algum modo, a imposição de regras e padrões racistas por parte da instituição é de alguma maneira vinculada à ordem social que ela visa resguardar. Assim como a instituição tem sua atuação condicionada a uma estrutura social previamente existente - com todos os conflitos que lhe são próprios -, o racismo que esta instituição venha a expressar é também parte desta mesma estrutura. As instituições são apenas a materialização de uma estrutura social ou de um modo de socialização que tem o racismo como um de seus componentes orgânicos. Dito de modo mais direto: as instituições são racistas porque a sociedade é racista (ALMEIDA, 2018, p. 36).

Falar de racismo estrutural não é afirmar que o racismo é intocável ou inquestionável. Ao contrário, a sociedade é formada por relações de poder envolvendo não apenas raças e etnias, mas colocando em intersecção a classe, o gênero, a sexualidade, a geração, etc. Todos esses elementos vão gerar inúmeros conflitos e tensões. Essa tensão é também capaz de incidir sobre o padrão de funcionamento de 
determinadas instituições que privilegiem determinados grupos sociais. Significando "que as instituições também podem atuar de maneira conflituosa, posicionando-se dentro do conflito" (ALMEIDA, 2018, p, 37), ou também que há tensão dentro das instituições.

No caso dos quilombos essa tensão é notada constantemente. Ao considerar o recorte temporal entre os anos de 1970 até os dias atuais, em 2019, percebe-se que a potência dos movimentos quilombolas, articulados a outros movimentos de reexistências do campo e da cidade, aos parlamentares, universidades, artistas e outros setores da sociedade, conseguiram afirmar a importância constitucional do Art. 68 da Constituição Federal de 1988 e do Decreto 4.887/2003. Ao mesmo tempo, pela força da presença daqueles setores que também se articulam para manterem os privilégios existem os ataques e a obstrução de políticas que ao combaterem o racismo, combatem também a sociedade que o produz.

\section{Conclusão}

A não-proteção dos territórios quilombolas e mais do que isso, a própria compreensão de que os e as quilombolas não são importantes para a constituição da nação, se apresenta quando são desvelados os dados sobre a regularização fundiária no Brasil. A Bahia, território com maior quantitativo de comunidades quilombolas certificadas pela Fundação Cultural Palmares apresenta inúmeros casos em que o impedimento do processo de regularização fundiária impacta violentamente não apenas o território ou a natureza, mas também os corpos dos negros e negras aquilomboladas.

A obstrução dos procedimentos nas mais diversas etapas da regularização fundiária, quando não questionada não contribui para a constituição de uma nação que respeite os direitos dos povos e das comunidades tradicionais, dentre eles os quilombos, conforme se compromete o Brasil através de diversos acordos internacionais, como a Convenção 169 da Organização Internacional do Trabalho.

É necessário assumir que o racismo está presente na vida cotidiana na sociedade brasileira, incluindo aqui as instituições. Se a ordem é racista, as instituições são também racistas, como já foi afirmado no tópico anterior. Sílvio Almeida afirma: "Em uma sociedade em que o racismo está presente na vida cotidiana, as instituições que não 
tratarem de maneira ativa e como um problema a desigualdade racial irão facilmente reproduzir as práticas racistas já tidas como 'normais' em toda a sociedade" (ALMEIDA, 2018, p. 37).

A partir da compreensão apresentada nesse texto é possível afirmar que a nãoregularização dos territórios quilombolas na Bahia e no Brasil é responsabilidade da ordem que mantém e garante com que a sociedade e suas instituições reproduzam o racismo estrutural. Essa reprodução não é feita sem tensões de grupos que tentam romper esse ciclo que se arrasta no Brasil e mais especificamente na Bahia desde 1501, quando foi iniciada a colonização das águas e terras de Kirimurê ${ }^{10}$.

\section{REFERÊNCIAS}

ALENTEJANO, Paulo. A centralidade da questão fundiária no cenário agrário brasileiro no século XXI. Encontro de Geógrafos da América Latina. 2015.

ALMEIDA, Alfredo Wagner B. Terras tradicionalmente ocupadas. Processos de territorialização e movimentos sociais. Revista Brasileira de Estudos Urbanos e Regionais, vol. 6, n.1, p.9-32, 2004. https://doi.org/10.22296/2317-1529.2004v6n1p9

ALMEIDA, Silvio. O que é racismo estrutural? Belo Horizonte: Letramento, 2018. ANJOS, Rafael Sanzio dos. Cartografia e Cultura: Territórios dos remanescentes de quilombos no Brasil. VIII Congresso Luso-Afro-Brasileiro de Ciências Sociais. 2004 BRASIL. Decreto $n^{0}$ 4.887. 2003.

\section{BRASIL. Artigo 68 do Ato das Disposições Constitucionais Transitórias. 1988.}

CAÑETE, Voyner Ravena Cañete; CAÑETE, Thales Maximiliano Ravena. Por uma sociologia do campo jurídico na/da Amazônia: as populações tradicionais amazônicas em foco. Revista Sociologia Jurídica, n. 13, jul/dez. 2011. Disponível em $<$ https://sociologiajuridicadotnet.wordpress.com/por-uma-sociologia-do-campojuridico-nadaamazonia-as-populacoes-tradicionais-amazonicas-em-foco/>. Acesso em: 16. Jun. 2017.

CARRIL, Lourdes. Quilombo, favela e periferia: a longa busca da cidadania. São Paulo: Annablume; FAPESP, 2006.

10 - Nome dado pelos Tupinambá ao que atualmente conhecemos por Baía de Todos os Santos, nome rebatizado pelos Portugueses em 1501, após a invasão, colonização, resistência, assimilação e extermínio dos povos indígenas, principalmente dos Tupinambás ali existentes. 
CASTRO, Edna. Território, biodiversidade e saberes de populações tradicionais. In CASTRO, PITON (Org). Faces do Trópico úmido: Conceitos e questões sobre desenvolvimento e meio ambiente. Belém: Cejup, 1997. P.221-242.

CESAIRE, Aimé. Discurso sobre o colonialismo. Porto: Poveira, 1971.

CORRÊA, Gabriel Siqueira. O branqueamento do território como dispositivo colonialidade do poder: notas sobre o contexto brasileiro. In: CRUZ, Valter do Carmo. Geografia e Giro Descolonial: Experiências, ideais e horizontes de renovação do pensamento crítico. Rio de Janeiro: Letra Capital, 2017.

FANON, Frantz. Pele negra, máscaras brancas. Salvador, BA: EDUFBA, 2008.

$\begin{array}{lllll}\text { Fundação Cultural Palmares. Dados } & \text { Quilombolas. } & \end{array}$ https://doi.org/10.7476/9788523212148

INCRA. INSTITUTO NACIONAL DE COLONIZAÇÃO E REFORMA AGRÁFIA. Relatório Técnico de Identificação e Delimitação do Território da Comunidade Quilombola de Rio dos Macacos. Salvador, 2012.

INCRA. Dados de regularização fundiária do Brasil. 2018.

LACOSTE, Yves. A geografia - isso serve, em primeiro lugar, para fazer a guerra. Campinas, SP: Papirus, 1988.

MARTINS, José de Sousa. A chegada do estranho. São Paulo: HUCITEC, 1993.

MOORE, Carlos. Racismo \& Sociedade: novas bases epistemológicas para entender o racismo. 2. Ed. Belo Horizonte: Nadyala, 2012.

MOURA, Clovis. Rebeliões da senzala: quilombos, insurreições, guerrilhas. 3. ed. São Paulo, SP: Ciências Humanas, 1981

QUIJANO, Anibal. Colonialidade do poder, eurocentrismo e América Latina. In: LANDER, Edgardo (Org). A colonialidade do saber: eurocentrismo e ciências sociais. Perspectivas latino-americanas. Ciudad Autónoma de Buenos Aires, Argentina: CLACSO, 2005. Colección Sur Sur. p. 227-278.

RATTS, Alex. As etnias e os outros: as espacialidades dos encontros/confrontos. In: Espaço e cultura. UERJ, Rio de Janeiro, N 17-18, Jan/Dez de 2004. p.77-89.

SANTOS, Renato Emerson. O movimento negro brasileiro e sua luta antirracismo: por uma perspectiva descolonial. In: CRUZ, Valter do Carmo. Geografia e Giro Descolonial: Experiências, ideais e horizontes de renovação do pensamento crítico. Rio de Janeiro: Letra Capital, 2017.

SEPPIR. Plano Nacional de Desenvolvimento Sustentável dos Povos e Comunidades Tradicionais de Matriz Africana 2013-2015. 2013.

SHIVA, Vandana. Monoculturas da Mente. São Paulo: Gaia, 2003. 